\title{
Vestes que falam \\ a tecelagem e as personagens femininas dos poemas homéricos
}

Lilian Amadei Sais

RESUMO: O objetivo desse artigo é mostrar de que forma as vestes são apresentadas na sociedade homérica. Podemos observar que a tecelagem, sendo um trabalho exclusivamente feminino em Homero, é importante para que as mulheres obtenham prestígio e fama. A Odisseia nos mostra que o oferecimento de roupas como presente era uma etapa importante na cena típica de hospitalidade, consolidando os laços existentes entre anfitrião e hóspede. Por fim, argumentamos que na narrativa homérica a vestimenta possui capacidade de comunicação.

PALAVRAS-CHAVE: Sociedade homérica; personagens femininas; tecelagem.

\section{Making vesture speak weaving and female character in Homeric Poetry}

ABSTRACT: The aim of this article is to demonstrate in which ways vesture is presented in Homeric society. We argue that weaving, being exclusively female work in Homer, is important so that women may obtain prestige and fame. The Odyssey shows us that offering clothes as a gift was an important step in the hospitality type-scene, consolidating host-guest friendship. Finally, we argue that in Homeric narrative vestment is able to communicate. KEYWORDS: Homeric society; female character; weaving.

A llíada e a Odisseia são consideradas os textos mais antigos da literatura ocidental. Não sabemos muito sobre a forma como os poemas foram compostos, embora muitos avanços já tenham sido feitos nessa área. Hoje se aceita consensualmente que os poemas são fruto de uma tradição épica de composição oral, o que nos leva a acreditar que eles tenham se formado ao longo de séculos. A data em que eles teriam sido postos por escrito ainda produz muita discussão: na melhor das hipóteses, isso poderia ter sido feito no século VIII a.C., embora a maior parte dos pesquisadores defenda que o registro escrito dos poemas não tenha se dado antes do século VI a.C. Sobre quem seria Homero e qual seria a participação dele na composição dos poemas na forma como eles nos chegaram, mais polêmica: alguns defendem que ele sequer existiu, e seu nome seria uma brincadeira com o grego e significaria "aquele que não vê", fazendo alusão ao fato de que os aedos (cantores que apresentavam suas composições épicas) eram, em sua maioria, cegos; outros acreditam que ele é o grande responsável pela qualidade do material que nos chegou.

A llíada, poema bélico, canta a briga entre Aquiles, melhor guerreiro grego, e Agamêmnon, chefe das tropas, e suas consequências funestas para os aqueus. São narrados no poema cerca de dois meses do nono ano da guerra. A Odisseia, poema de retorno, canta a volta para a casa, finda a guerra, de Odisseu, um dos principais guerreiros gregos. Ele demora dez anos para conseguir chegar à sua terra natal, Ítaca. Quando ele finalmente chega,

Doutoranda em Letras Clássica (FFLCH/USP). Email: <liliansais@gmail.com>. 
contudo, o retorno ainda não está concluído: ele precisa reinstaurar a ordem em sua própria casa, que foi tomada pelos cento e oito pretendentes de sua mulher, Penélope.

Não temos notícias de que havia na tradição oral épica mulheres desempenhando a função de aedo. A sociedade dos poemas homéricos traz homens e mulheres atuando em esferas diferentes: aos homens cabem os assuntos de política, guerra, e os discursos (falas de autoridade, nas quais se pode inserir a função de cantor/ aedo), já às mulheres cabe o trabalho doméstico, no qual se destaca a produção de vestes, e a lamentação dos mortos.

A personagem homérica Penélope é quase indissociável da figura de tecelã e, portanto, paradigmática para a questão. Isso se deve ao famoso estratagema da mortalha de Laertes, narrado três vezes ao longo da Odisseia: sem saber se o marido, Odisseu, está vivo ou morto, e, após anos do fim da Guerra de Troia sem que o herói completasse seu retorno à terra natal, Penélope se vê cortejada por cento e oito pretendentes, que invadem seu palácio, consomem seus bens e exigem que a rainha escolha um dentre eles para contrair novas bodas. Diante dessa tensa e insustentável situação, Penélope promete que escolherá um novo marido assim que terminar de tecer a mortalha de seu sogro, Laertes. Penélope passa os dias tecendo a mortalha, mas à noite, sorrateiramente, desfaz tudo que havia tecido durante o dia, fazendo com que sua tarefa nunca termine. Desse modo, a astuta consorte do multiastucioso por excelência, Odisseu, consegue enrolar os pretendentes em sua trama durante três anos. Seu dolo, contudo, é descoberto e delatado aos pretendentes por uma serva infiel. Quando a Odisseia começa a ser narrada, o ardil de Penélope foi descoberto há pouco tempo, e há grande pressão sobre ela para que tome uma decisão definitiva. A primeira vez que o estratagema da mortalha é narrado no poema é no Canto II, vv. 85-110, quando Antínoo relembra a Telêmaco a artimanha de sua mãe como tecelã:

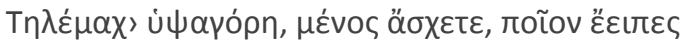

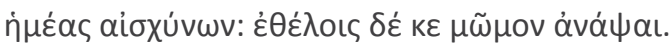

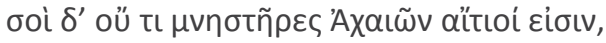

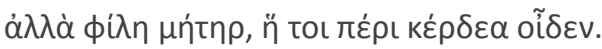

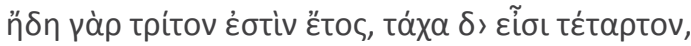

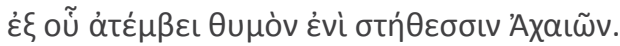

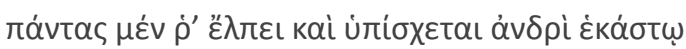

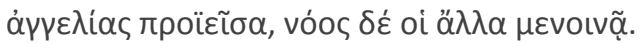

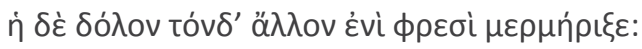

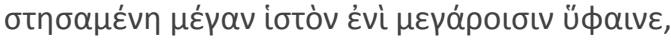

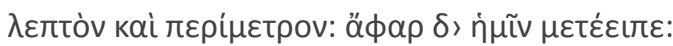

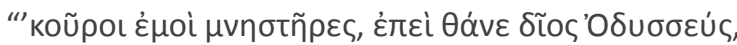

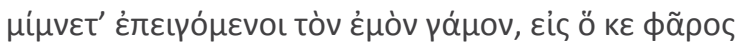

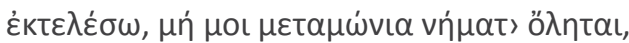

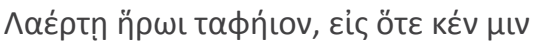

Making vesture speak: weaving and female character in Homeric Poetry

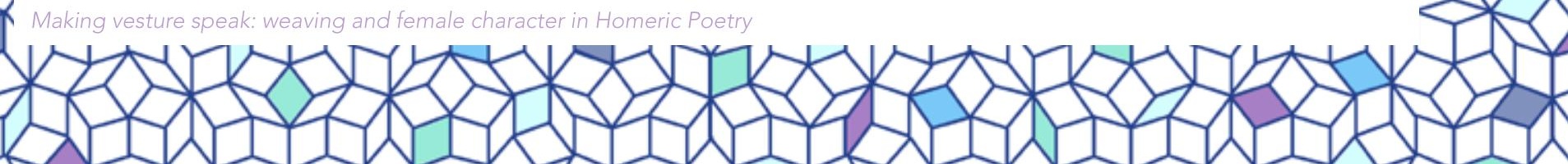




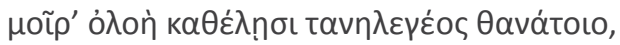

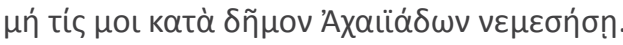

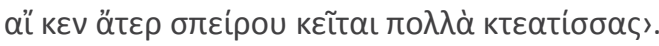

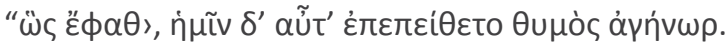

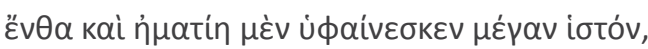

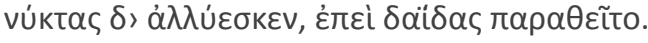

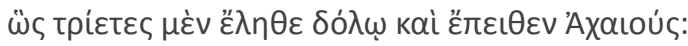

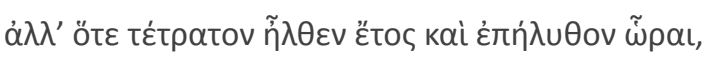

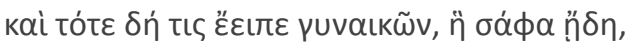

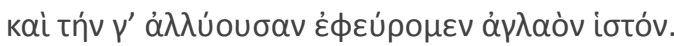

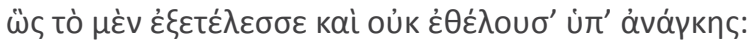

Telémaco descarado, irreprimível na tua fúria, que vergonhas nos lançaste à cara! Será que nos queres censurar?

Pois fica sabendo que não são os pretendentes os culpados, mas a tua querida mãe, sobremaneira astuciosa!

Na verdade já vamos no terceiro ano - em breve virá o quarto em que ela engana os corações dos Aqueus.

A todos dá esperança e a cada homem manda recados, mas o seu espírito está voltado para outras coisas. Também este engano congeminou em seu coração: colocando um grande tear nos seus aposentos amplo, mas de teia fina - foi isto que nos veio a declarar:

'Jovens pretendentes! Visto que morreu o divino Ulisses, tende paciência (embora me cobiceis como esposa) até terminar esta veste - pois não quereria ter fiado a lã em vão uma mortalha para o herói Laertes, para quando o atinja o destino deletério da morte irreversível, para que entre o povo nenhuma mulher me lance censura de que jaz sem mortalha quem tantos haveres granjeou.'

Assim falou e os nossos corações orgulhosos consentiram. Daí por diante trabalhava de dia ao grande tear, mas desfazia a trama de noite à luz das tochas.

Deste modo durante três anos enganou os Aqueus.

Mas quando sobreveio o quarto ano, volvidas as estações, uma das mulheres, que estava por dentro, contou-nos o sucedido, e encontrámo-la a desfazer a trama maravilhosa.

De maneira que a terminou, obrigada, contra sua vontade.

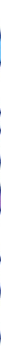


Em Homero, fiar e tecer são tarefas exclusivamente femininas. Assim, ao longo da llíada e da Odisseia, não apenas Penélope se dedica a essa tarefa, mas inúmeras personagens femininas são representadas realizando esse tipo de atividade doméstica. Uma passagem significativa em que isso ocorre está narrada na llíada: trata-se da primeira aparição de Helena, no Canto III do poema: a deusa Íris vai como mensageira avisá-la de que Páris e Menelau combaterão em duelo para decidir a guerra. São os versos $121-128^{2}$ que descrevem a cena:

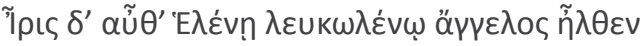

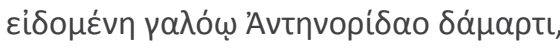

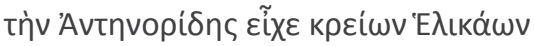

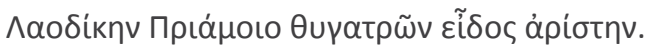

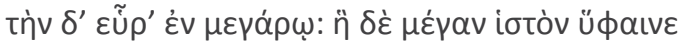

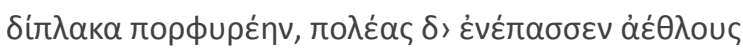

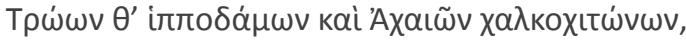

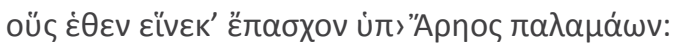

Porém Íris chegou como mensageira junto de Helena de alvos braços,

assemelhando-se à cunhada, esposa do filho de Antenor:

aquela a quem desposara o poderoso Helicáon, filho de Antenor,

Laódice, a mais destacada na beleza das filhas de Príamo.

Encontrou-a no palácio, tecendo uma grande tapeçaria

de dobra dupla, purpúrea, na qual ela bordava muitas contendas

de Troianos domadores de cavalos e Aqueus vestidos de bronze:

contendas que por causa dela tinham sofrido às mãos de Ares.

Muito já se comentou sobre como Helena, tecendo os fatos da Guerra de Troia, assemeIha-se em grande medida ao próprio poeta que canta a llíada: enquanto a narração deste é oral, a daquelaé visual, mas ambas relatam os mesmos acontecimentos. Numa sociedade machista em que a mulher era constantemente silenciada, a tecelagem era uma das poucas formas que ela tinha de se comunicar. Não são poucos os mitos que abordam o poder de comunicação pictórico dos mantos e das vestes produzidos pelas mulheres. Um dos mais eloquentes talvez seja o de Filomela, irmã de Procne: aquela é estuprada pelo marido desta, e ele corta a sua língua para que ela não possa contar o fato a ninguém. Ela, contudo, borda a história em um pedaço de tecido, com o qual presenteia a irmã, que entende a mensagem e, para se vingar do marido, mata o filho deles e o serve para que ele coma. Essa história é mais explorada pelos poetas latinos que pelos gregos, mas constitui um bom exemplo daquilo que afirmamos.

Helena parece consciente de que será uma figura que fará parte da História, ao dizer a Heitor os versos que seguem (II. VI, vv. 357-358): "Sobre nós fez Zeus abater um destino doloroso, para que no futuro/ sejamos tema de canto para homens ainda por nascer". Para os gregos, em um mundo no qual não havia escrita, entrar para a História, conquistar "fama

${ }^{2}$ Todos os trechos homéricos aqui citados são da tradução portuguesa de Frederico Lourenço.

Making vesture speak: weaving and female character in Homeric Poetry 


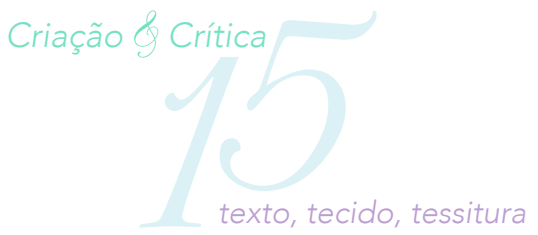

imperecível", ou seja, uma glória imortal, estava associado a se tornar tema de poesia, pois ela tinha essa função imortalizadora.

Do mesmo modo que ocorre na llíada, em sua primeira aparição na Odisseia, Helena entra em cena com suas servas carregando para junto dela objetos úteis a fiar, o que a conecta com a imagem mais ampla de tecelã. A cena está narrada poucos versos antes de Helena assumir a função de narradora e apresentar um discurso elaborado sobre um episódio da Guerra de Troia que envolve Odisseu. Nele, Odisseu teria entrado disfarçado de mendigo em Troia, para conseguir informações sobre o campo inimigo, e apenas Helena o teria reconhecido. Ela o teria banhado e oferecido vestes novas, e, após pronunciar um juramento, Odisseu teria lhe contado todo o plano dos Aqueus, antes de partir rumo às naus, matando pelos caminhos certa quantidade de troianos. Mulheres assumindo a palavra para enunciar um discurso não é algo tão comum nos poemas homéricos. Contudo, uma leitura cuidadosa pode nos apontar a ligação que há nesses textos entre a tecelagem, a astúcia e a fala.

A ligação entre tecelagem e engano está bem enraizada no texto homérico: na Odisseia, o verbo "tecer" (huphainô) possui como objeto palavras como "astúcia" (mêtis) e "dolo" (dolos) - ver, por exemplo, Od. IV, v. 678; Od. V, v. 356; Od. IX, v. 422; Od. XIII, v. 303, v. 386; em Homero, portanto, o verbo "tecer" pode ser usado no sentido literal, de tecer vestes, ou no sentido metafórico, de tecer uma astúcia, um dolo ou um engano. Ao mesmo tempo em que o narrador da Odisseia não é nem pró nem contra nenhuma personagem feminina, e mantém-se neutro mesmo no que se refere à dúbia Helena (que deixou seu marido e sua filha em Esparta e partiu para Troia com Páris, o troiano que estava em sua casa como hóspede de Menelau, levando inúmeros tesouros do palácio consigo), várias personagens masculinas ao longo do poema maldizem as mulheres, tais como Agamêmnon, os pretendentes e Telêmaco. As mulheres são - ou ao menos possuem recursos para ser - perigosas, e nesse sentido a astúcia feminina é um desses recursos a serem temidos.

A dubiedade feminina, para Bergren (1983: 69-70), está relacionada a uma habilidade de falar de dois modos: ao mesmo tempo em que as mulheres podem ser vozes da verdade, como profetizas e professoras, podem também dar à mentira forma e aparência de verdade. Para a pesquisadora, a Teogonia introduz a relação entre a linguagem e o feminino no pensamento grego antigo, nos versos 22-32, em que as Musas (que dentro do pensamento antigo são as responsáveis pelo canto) afirmam que podem dizer tanto verdades como, se quiserem, mentiras que se assemelham a verdades.

First, what is the nature of the Muses' speech? They claim to know two modes, both "false things like to reality" and "true things", and to be able to switch from one to the other at will. What is their purpose in making this claim? Evidently, it is to declare the extent of their knowledge - note the repetition of idmen "we know" (...). Accordingly, they claim control of both truth and falsehood, since, as Odysseus proves when he tells pseudea homoia etumoisin about himself (Od. 19. 203) (the only other instance of this phrase), the ability to utter falsehood implies and requires knowledge of the truth. (...)

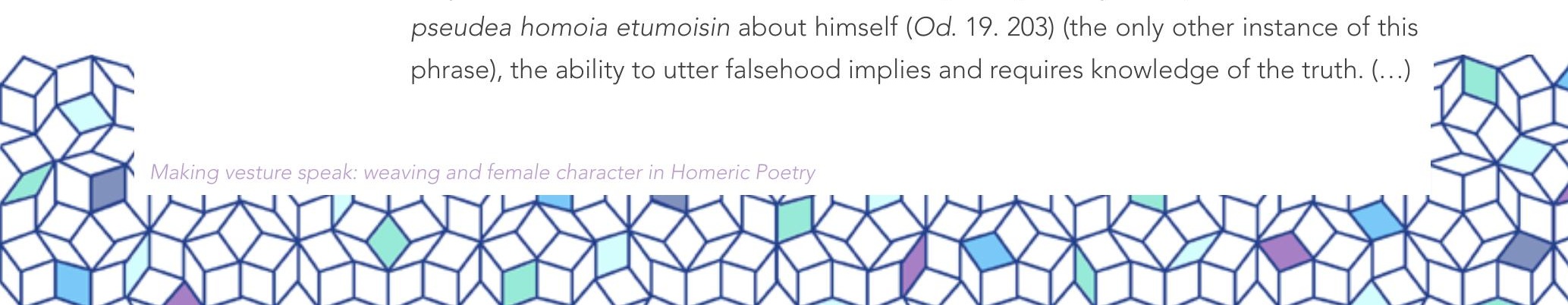




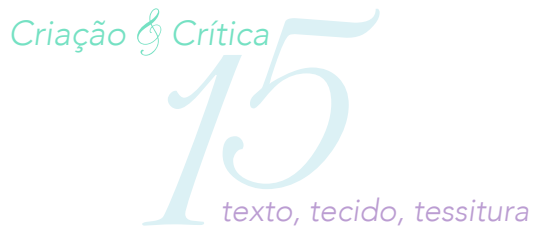

These two modes of the Muses' discourse parallel the two kinds of speech attributed to women throughout Greek tradition. (BERGREN, 1983, p. 69-70).

Para qualquer interlocutor cujo conhecimento sobre determinado ponto seja inferior ao do falante, a fala em si permanece ambígua, sendo impossível determinar-lhe a veracidade ou a ausência dela. Como as mulheres são seres potencialmente enganosos, "feminine silence is idealized, if not realized, in Greek thought, while the unrestrained speech of women is frequently equated with lack of sexual restraint." (FLETCHER, 2008, p. 77).

Dessa forma, qual seria a ligação entre fala e tecelagem?

Na sociedade grega antiga, falar não é uma atividade que cabe às mulheres. Em vez de falar, elas tecem. Enquanto isso, os homens falam, cuidam das questões de política, guerra e sociedade, etc. As mulheres, silenciadas, tecem, produzindo uma "fala metafórica", ou seja, fazendo um "material silencioso falar" 3 . Bergren (1983, p. 72) afirma:

Greek culture inherits from Indo-European a metaphor by which poets and prophets define themselves as "weaving" or "sewing" words. That is, they describe their activity in terms of what is originally and literally woman's work par excellence. They call their product, in effect, a "metaphorical web". But which, then, is the original and which is the metaphorical process? Is weaving a figurative speech or is poetry a figurative web? The question cannot be decided. Weaving as the sign-making activity of women is both literal and metaphorical, both original and derived. It is, like the Muses' speech, ambiguously true speech and an imitation of true speech.

Em algumas passagens da Odisseia, vestes produzidas por personagens femininas são elementos-chave: elas comunicam. Citaremos, na sequência, três exemplos que consideramos eloquentes para estabelecer a questão: Helena no Canto XV, Arete no Canto VII e Penélope no Canto XIX. Vamos a eles.

Os cantos I-IV da Odisseia formam aquilo que se convencionou chamar "Telemaqueia", pois têm como personagem central Telêmaco, filho de Odisseu. $\bigcirc$ jovem, prestes a se tornar adulto, empreende viagens em busca de notícias sobre seu pai, por conselho da deusa Atena, disfarçada de Mentes (Od. I, vv. 280-292). Ele chega, no Canto III, a Pilos, terra do sábio Nestor, e, no Canto IV, a Esparta, onde reina Menelau, com sua esposa Helena. Telêmaco é recebido no Canto IV por Menelau e Helena, mas a cena típica de hospitalidade só se encerra no Canto XV, com a oferta de presentes dos anfitriões para o hóspede.

A Odisseia, em sua condição de poema de retorno (nóstos) e, consequentemente, de poema de viagem, tem como um de seus temas principais a hospitalidade. Os diferentes viajantes ali apresentados (além de Odisseu, temos narradas também, por exemplo, as viagens de Telêmaco e Menelau) dependem da hospitalidade de seus anfitriões para estabelecerem com sucesso tanto sua estadia em terra estrangeira como o término de sua viagem. Não surpreende, portanto, a afirmação de Alcínoo em Od. VIII, vv.546-547:

Bergren (1983: 72).

Making vesture speak: weaving and female character in Homeric Poetry

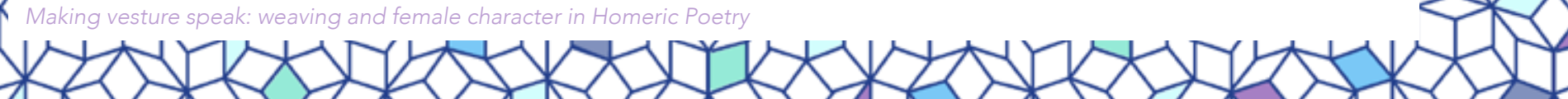




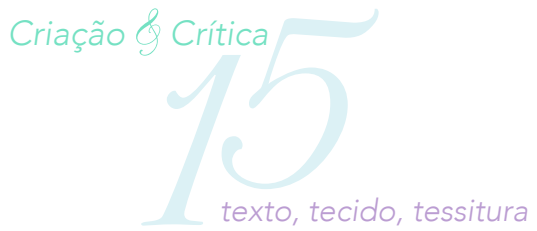

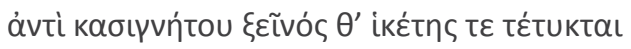

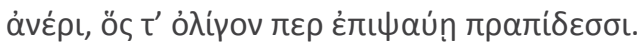

Um estrangeiro e suplicante é como um irmão

para o homem que atinja o mínimo de bom senso.

Do mesmo modo, os versos formulares enunciados por Odisseu em três diferentes momentos (VI, w.121-122, IX, vv. 175-176, XIII, 201-202) sublinham a oposição entre violência, injustiça, desmedida, de um lado, e hospitalidade e piedade aos deuses, de outro. Nas três passagens, após chegar a uma nova terra, o herói se questiona sobre os homens que ali habitam:

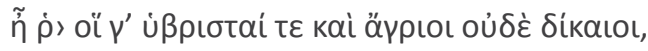

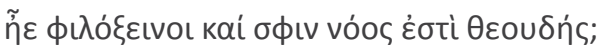

Serão eles homens violentos, selvagens e injustos?

Ou serão dados à hospitalidade e tementes aos deuses?

O ciclo troiano contemplado pela obra de Homero é, em última instância, todo ele resultado de uma relação imprópria de hospitalidade: Páris rompe os laços de xenia ao levar consigo Helena para Troia, uma vez que Menelau era seu anfitrião, o que leva à Guerra de Troia (que fornece matéria para a llíada) e, findas as batalhas, ao retorno dos aqueus para casa (o que fornece matéria para a Odisseia).

A oferta de presentes ao hóspede, além de ser uma forma de honrar o hóspede, é um passo importante no estabelecimento dos laços de hospitalidades entre duas casas. Quando Telêmaco anuncia que irá partir de Esparta, Menelau e Helena apressam-se em ir à sala onde estão guardados seus tesouros. Menelau escolhe uma taça de asa dupla e pede ao filho que pegue uma bacia de prata para presentear o hóspede; ela, por sua vez, escolhe uma veste que ela mesma produzira, que o poeta nos diz que reluz como as estrelas. Esse elogio do narrador às vestes produzidas por Helena nos lembra da habilidade de Helena nos afazeres domésticos e volta a associá-la à imagem de mulher virtuosa, que cumpre a tarefa que the cabe dentro de sua condição feminina. A cena de Helena ofertando a veste está narrada entre os versos 123-130:

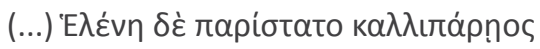

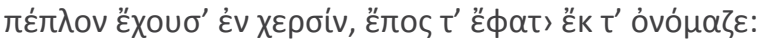

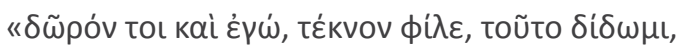

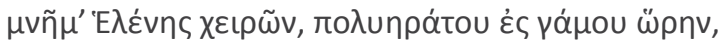

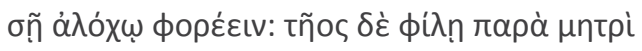

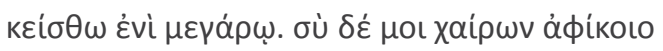

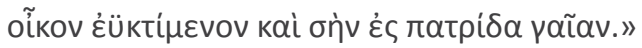

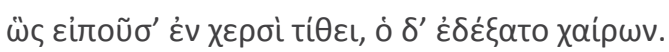

Making vesture speak: weaving and female character in Homeric Poetry 


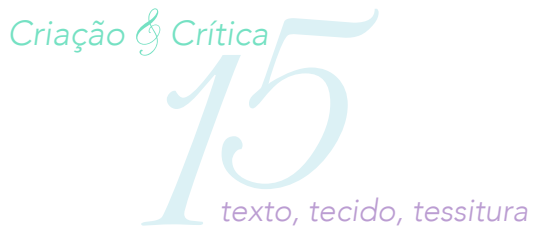

E aproximou-se Helena de lindo rosto, segurando nas mãos a veste; e falando assim Ihe dirigiu a palavra:

"A ti, querido filho, ofereço este presente, recordação

das mãos de Helena, para no dia do teu desejado casamento a tua noiva vestir. Que até lá a veste seja guardada no palácio pela tua mãe amada. Quanto a ti, que chegues bem à tua bela casa e à tua terra pátria."

Assim falando pôs-lhe a veste nas mãos; e ele a recebeu, feliz.

Sobre isso, Mueller analisa que:

When Helen offers Telemachus a robe she herself has made in book 15 of the Odyssey, she bestows her gift with the hope that it will act as "a monument to the hands of Helen". Helen's pep- los attests to the potential for handcrafted objects to immortalize those who have made them. It also serves as a useful reminder that even within Homeric epic, which in itself is an outstanding example of male kleos, various technologies exist for men and women to craft their own kleos. (...)

Travelers in the Odyssey depend on the hospitality (xenia) of the hosts they visit. (...) While the offer of "cloak and tunic" satisfies a basic need on the part of the guest, it also implies a broader range of social obligations. Clothing functions as a metonym and physical embodiment - of the relationship of hospitality between the host and his guest, and symbolizes their commitment to house and protect one another.

Given that weaving is a female occupation in the Homeric poems, it is not surprising to find women also offering clothing as a parting gift (xeinêion). Weaving and textiles comprise a sphere of xenia in which women interact with guests, as well as with one another, semi-autonomously. Whereas male heroes typically had their glorious deeds circulated through song, as in the famous case of Achilles singing kléa andrôn in the Iliad (9. 189), female characters in Homer immortalize their names through more diverse media. Weaving, while analogous to poetic song, was a realm in which women did not compete directly with men. Women could win fame from the work of their hands without compromising male kléos. (MUELLER, 2010, p. 1-2)

Mueller destaca a habilidade nas tarefas de manufaturas domésticas como elemento capaz de atribuir kléos (glória) à personagem feminina. Assim, quando Helena oferta as vestes que produzira a Telêmaco, ela afirma que elas são "uma recordação/ monumento das mãos de Helena". Essa afirmação parece afirmar, de uma só vez, tanto que quem visse aquela veste saberia que ela havia sido feita por Helena, o que nos leva a crer que cada casa (oîkos) produzia vestes com características bastante próprias, quanto que a atividade da tecelagem, sendo realizada de maneira exímia, poderia atribuir fama, glória, a sua executora. Nesse sentido, é como se a veste fosse um símbolo das mãos de quem a produziu, como se a veste, por si só,

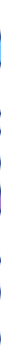


falasse de que casa (oîkos) provém e qual é a excelência de sua tecelã. As cenas que envolvem Arete e Penélope parecem nos indicar as mesmas coisas, como veremos.

No início do Canto VI da Odisseia, o narrador conta que Odisseu dorme, após vencer o naufrágio e chegar à Feácia, enquanto Atena vai para o palácio do rei Alcínoo para, postada sobre a cabeça de Nausícaa adormecida, dizer-lhe que o dia de seu casamento se aproxima e que ela deve, portanto, ir lavar roupas. Com esse artifício, a deusa garante que a jovem encontre o multiastucioso: é a partir daí que se dará a recepção dos Féacios a Odisseu. Após o encontro entre Nausícaa e Odisseu, ela oferece ao recém-chegado hóspede comida e vestes. No fim do encontro, ela instrui Odisseu sobre o que ele deve fazer para ser recebido como hóspede pelos Feácios e orienta-o para que suplique à sua mãe, Arete, em primeiro lugar. Em sua fala (Od. VI, vv. 303-315), Nausícaa diz que ele encontrará a mãe próxima à lareira, fiando lã purpúrea como o mar (vv. 303-315):

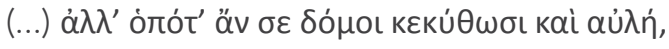

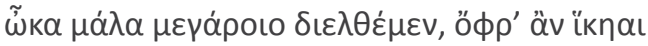

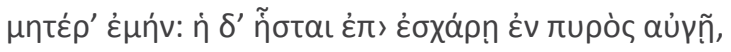

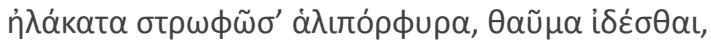

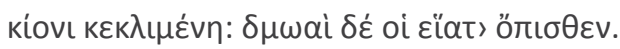

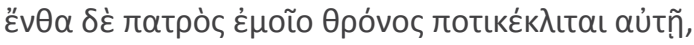

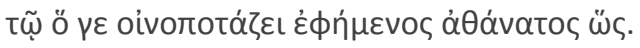

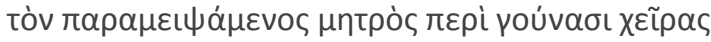

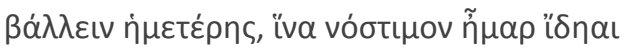

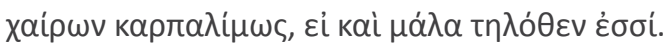

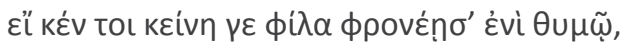

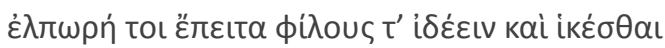

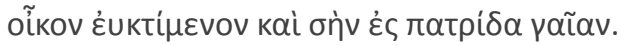

Quando te cercarem os edifícios e o pátio, vai depressa para a grande sala, onde encontrarás a minha mãe: ela senta-se à lareira, à luz do fogo, e fia a lã, purpúrea como o mar, maravilha de se ver!, reclinada contra uma coluna. As servas sentam-se à sua volta.

Aí, contra a mesma coluna, está o trono de meu pai, onde se senta como um imortal a beber o seu vinho.

Passa apenas por ele; atira-te antes aos joelhos da minha mãe, para os abraçares, para que vejas o dia do teu regresso, depressa regozijando-te, apesar de teres vindo de tão longe. Se ela te acolher com gentileza no seu coração, há esperança de que revejas a família e regresses à tua casa bem construída e à tua terra pátria. 
A jovem se refere ao trabalho têxtil da mãe ("maravilha de se ver!", na tradução de Frederico Lourenço) com $\theta \alpha \tilde{\mu} \mu \alpha$ i $\delta \varepsilon ́ \sigma \theta \alpha$, expressão geralmente utilizada por mortais em relação a pessoas e objetos imortais ${ }^{4}$. O louvor às vestes que ela produz é significativo, posto que, conforme mencionado, o trabalho manual realizado pelas mulheres deve ser considerado uma das formas que elas possuíam de atingir sua glória (kléos).

Odisseu segue à risca as instruções recebidas. Arete, no entanto, só assume a palavra quase cem versos após a realização da súplica, depois que os demais Feácios já se retiraram do palácio. Em uma conversa reservada que inclui apenas ela, seu marido Alcínoo e Odisseu, a rainha pergunta diretamente a este último quem ele é, como havia conseguido aquelas vestes, e se não tinha dito que chegara após vaguear pelo mar (Od. VII, vv. 237239). O narrador fornece uma informação importante para a interpretação da cena, revelando imediatamente antes da fala da rainha que Arete reconhecera a capa e a túnica que Odisseu vestia, pois ela mesma as tecera, junto com suas servas. Arete, portanto, é capaz de identificar que uma veste foi produzida em sua casa (oîkos), mesmo sem um exame mais detalhado da mesma, o que mais uma vez parece contribuir para que acreditemos que cada casa (oîkos) possuía sua própria forma distintiva de produzir vestes.

Chegamos finalmente à Penélope, cujo mito é indissociável da imagem de tecelã virtuosa. Odisseu chega a Ítaca em Odisseia XIII, e a deusa que o protege, Atena, muda a sua aparência, para que ele possa se infiltrar em sua própria casa sem ser reconhecido, para então elaborar um plano de como se livrar dos pretendentes, os quais são uma grande ameaça.

A transformação de Odisseu em mendigo, executada por Atena em Od. XIII, coloca o herói no limite entre ser e não-ser; não se trata de um simples disfarce, mas sim de uma modificação na aparência do herói realizada de forma mágica. O mendigo é uma figura sem status social e, em certo sentido, anônima; como ninguém se importa com sua opinião, a posição de mendigo possibilita que ele observe as pessoas tais como elas são, livres de qualquer máscara ou disfarce; possibilita, também, que Odisseu descubra qual é a hospitalidade que cada um (Telêmaco, Eumeu, Penélope e, de outro lado, os pretendentes) oferece. Irreconhecível, Odisseu dará início à série de testes, etapa quase sempre obrigatória nas cenas típicas de reconhecimento, nas quais, após assegurar-se da lealdade de algumas personagens, o herói dá-se a revelar.

O canto XIX é chave nas tentativas de interpretar Penélope, dado que ela faz poucas aparições no salão, e aqui ela assume o papel central de anfitriã. Até a chegada de Odisseu a Ítaca, no canto XIII, Penélope sofre, chora, e obedece; sua única astúcia está no passado, e deu errado. Contudo, após a chegada de Odisseu, e principalmente a partir do canto XVII, Penélope é uma personagem mais ativa - e mais enigmática.

Em Od. XIX temos o encontro entre Penélope e o mendigo-Odisseu. É o reencontro entre marido e mulher após vinte anos - mas Penélope não sabe disso. Para ela, o homem que está diante de si é um estrangeiro, e tudo o que ela quer dele é tentar obter informações sobre o seu marido.

É no verso 53 do canto XIX que o narrador volta a sua atenção para Penélope; ela sai do seu quarto, semelhante a Ártemis ou Afrodite, e senta-se em uma cadeira de prata e marfim,

Ver De Jong, 2001, p. 167. 
digna, portanto, de uma figura real. A entrevista tem início no verso 104: Penélope parte diretamente para o questionamento acerca da identidade do herói. Em cenas de hospitalidade, primeiro oferece-se ao hóspede comida e bebida, para apenas depois interrogar sobre sua identidade. Essa, no entanto, não é uma recepção normal. $\bigcirc$ estrangeiro já está nesse oîkos há alguns dias; nem Penélope, nem mesmo Telêmaco têm controle absoluto sobre a casa. Não é tão estranho, portanto, que a rainha não ofereça ao mendigo uma refeição.

Odisseu rapidamente tira o foco da conversa sobre si e o lança à esposa; aliás, ele a chama de gúnai (v. 107), palavra que pode ser entendido como "senhora" ou como "esposa", e que pode ser encarada como uma nova ironia. Em seguida, Odisseu compara Penélope a um rei irrepreensível. Versos depois, diante da insistência de Penélope em saber a identidade do homem que está diante de si, Odisseu conta uma história falsa, que ficou conhecida como o "terceiro conto cretense". O primeiro conto cretense foi contado pelo herói para Atena e o segundo, para Eumeu. Aqui, no terceiro, Odisseu fala que se chama Éton e que deu hospitalidade ao filho de Laertes há vinte anos, quando os ventos Ihe desviaram do caminho para Troia e o lançaram a Creta, onde teria permanecido junto com seus companheiros por doze dias. O narrador usa então um símile fortíssimo para descrever a reação da rainha ao discurso de Odisseu, no qual a face de Penélope, de tão cheia de lágrimas, parece estar derretendo como derrete o gelo de um pico cheio de neve com os ventos do sul, típicos da primavera. Em seu ânimo, Odisseu sente pena da mulher, mas mantém seus olhos como se fossem de chifre ou ferro (vv.210-212): olhos de estátuas, imóveis, livres de lágrimas.

Apesar de tão fortemente comovida, Penélope decide testar a veracidade do relato e pede que o estrangeiro descreva as roupas de Odisseu. $O$ multiastucioso começa dizendo que já faz muito tempo, mas em seguida descreve minuciosamente os trajes. No fim de seu relato, menciona o arauto que o acompanhava. Penélope reconhece que se tratam de "sémata émpeda" (literalmente, sinais firmemente fincados no solo, ou seja, consistentes, concretos, enraizados). A descrição tão detalhada das roupas de Odisseu faz com que novamente ele fique mais presente. Fora Penélope quem fizera aquelas roupas, e Odisseu sabe disso, como também sabe que, por esse motivo, sua descrição detalhada das roupas faria que a rainha as reconhecesse - e até mesmo se sentisse elogiada. Além disso, já vimos (em Od. VII, vv. 230-239) que uma mulher sabe reconhecer as vestes que são produzidas em sua casa: lá, Arete as têm diante dos olhos, aqui, Penélope as visualiza através da descrição minuciosa feita por Odisseu. Sobre isso, Duarte analisa que:

Mais do que aceitar a veracidade do relato, Penélope reconhece Odisseu nas palavras do "hóspede", um reconhecimento que se encaixaria no segundo tipo descrito por Aristóteles, os que são urdidos pelo poeta. Os sinais materiais, as vestes, a joia, gnorísmata tradicionalíssimos, não se apresentam diante dos olhos, mas são descritos, como em várias outras cenas dessa espécie. No entanto, se as vestes descritas correspondem às de Odisseu, sabe-se que o encontro narrado nunca aconteceu. Trata-se de um paralogismo. Penélope acredita no estrangeiro valendo-se do seguinte raciocínio:

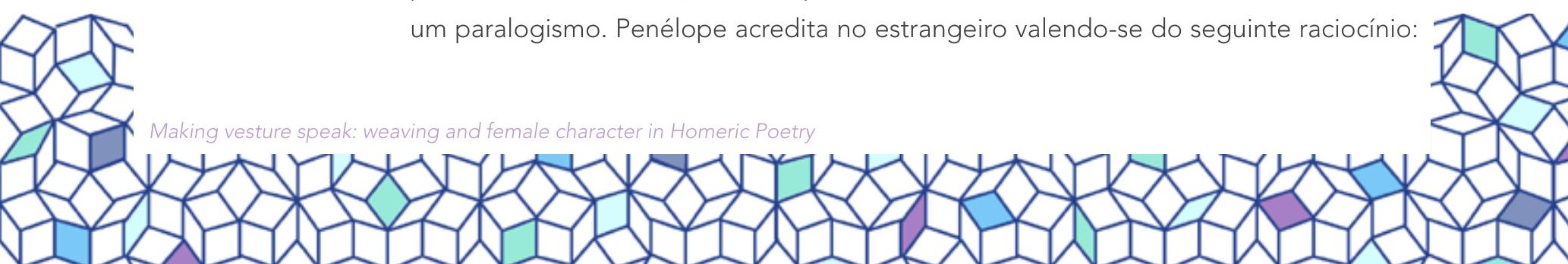


Odisseu possuía determinadas vestes e joia, que levara consigo para Troia; o hóspede soube descrevê-las à perfeição; conclui-se daí que o hóspede encontrou-se com Odisseu e que, portanto, fala a verdade. A falha lógica está no fato de que o estrangeiro poderia ter-se informado junto a alguém sobre as vestes que o herói portava ou, menos provável, mas verdadeiro nesse caso, o estrangeiro é o próprio Odisseu, hipóteses em que o encontro não teria se dado. (DUARTE, 2012, p. 152- 153).

O fato textualmente notável é que o sinal da descrição das roupas basta à Penélope para que ela acredite na veracidade do relato do suposto estrangeiro. A descrição das vestes de Odisseu comunica à Penélope a veracidade das palavras do seu interlocutor. É através dessa descrição que o mendigo-Odisseu ganha a confiança de Penélope, o que será importante para o desenrolar da conversa entre eles.

\section{Conclusão}

A tarefa relacionada ao estabelecimento de laços de hospitalidade que mais depõe quanto à ligação de xenia existente entre dois oíkos é a oferta das vestes, feita pelas muIheres ao seu hóspede. Conforme Pedrick (1988: 90) afirma, a cada vez que o hóspede vestir a roupa ofertada, a ligação de xenia estará marcada, evidenciada; pode-se inferir, também, que a qualidade do trabalho à mão de suas mulheres ajuda a atestar o valor de determinado oíkos. Não seria especular demais afirmar que cada oíkos ou, ao menos, que os oíkoi de cada região tinham sua marca particular, sua "assinatura", por assim dizer: Arete reconhece a veste de Odisseu assim que põe os olhos nele; Penélope confia no relato do mendigo ao ouvir a descrição deste acerca das vestes de Odisseu; mais eloquente em relação a essa hipótese, no entanto, é a afirmação de Helena em Od. XV, v. 126, na qual diz que a veste que oferta a Telêmaco é um monumento de suas mãos, sugerindo uma associação impossível de ser desfeita entre o objeto e o seu criador.

Vestes, que em Homero são tecidas exclusivamente por mulheres, representam uma importante função em cenas de reconhecimento e hospitalidade, e frequentemente há uma referência ao menos implícita às mãos de quem as concebeu.

\section{Referências Bibliográficas}

BERGREN, A. L. T. "Language and the female in early Greek thought." Arethusa 16, pp. 6995, 1983.

DUARTE, A. S. Cenas de reconhecimento na poesia grega. Campinas: Editora Unicamp, 2012. FLETCHER, J. "Women's space and wingless words in the Odyssey." Phoenix, Vol. 62, no. 1/ 2, pp. 77-91, 2008.

JONG, I. J. F de. A narratological commentary on the Odyssey. Cambridge: Cambridge University Press, 2001.

LOURENÇO, F. Ilíada. Lisboa: Ed Cotovia, 2005. Odisséia. Lisboa: Ed. Cotovia, 2003. 
MUELLER, M. "Helen's Hands: weaving for Kléos in the Odyssey." Helios, Vol. 37, No. 1, pp. 1- 21, 2010.

PEDRICK, V. "The hospitality of noble women in the Odyssey." Helios 15, pp. 85-101, 1988.

Recebido em: 12/08/2015 Aceito em: 06/11/2015

Referência eletrônica: SAIS, Lilian Amadei. Vestes que falam: a tecelagem e as personagens femininas dos poemas homéricos. Criação \& Crítica, n. 15, p. 7-19, dez. 2015. Disponível em: <http://revistas.usp.br/criacaoecritica>. Acesso em: dd mmm. aaaa.

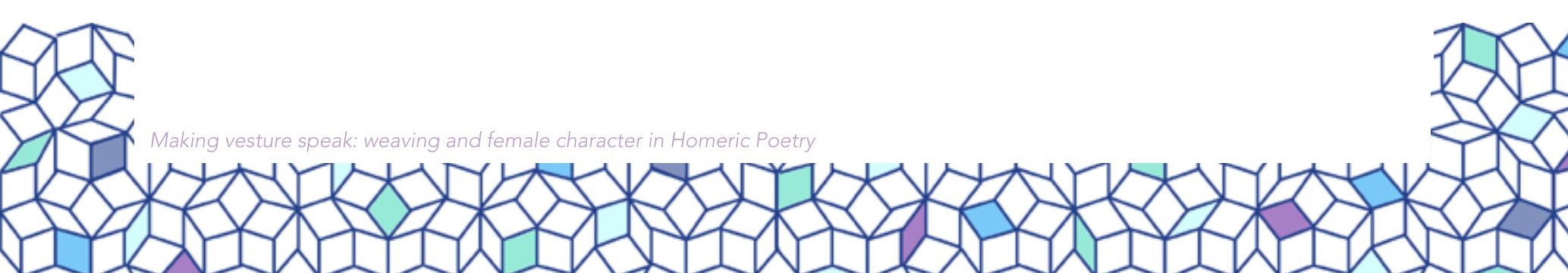

